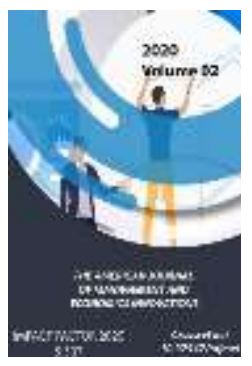

\title{
Assessing The Effectiveness Of Investment Projects Taking Into Account Factors Of Uncertainty, Risk And Inflation
}

\author{
Atabaeva Zamira Abduzhalilovna \\ Senior Lecturer, Department Of Accounting And Auditing, Ferghana Polytechnic Institute, \\ Uzbekistan
}

Journal Website: http://usajournalshub.c om/index,php/tajmei

Copyright: Original content from this work may be used under the terms of the creative commons attributes 4.0 licence.

\section{ABSTRACT}

The article presents the results of the study and the conclusions and recommendations that follow from them. Used statistical data, data from government agencies, materials of scientific conferences, Internet resources, the results of their own research and calculations. Research methods: methods of statistical and financial analysis, analysis of expert assessments and others.

\section{KEYWORDS}

Investment activity, the efficiency of planned investment projects, investment planning, risk level, sustainability assessment.

\section{INTRODUCTION}

One of the ways to stabilize and develop the economy is to expand investment activities, attract large investments in various sectors of the country's economy. In recent years, the Republic has adopted a wide range of measures to radically improve the business and investment climate, stimulate direct investment, strengthen investor confidence in the consistency of state policy in this direction and increase the responsibility of government agencies in working with investors [1, 2]. In the process of investment planning, an important role is given to the analysis and assessment of the effectiveness of planned investment projects. Both the state and private investors and credit institutions that finance investment projects are interested in improving the quality of evaluation of investment projects [3-7]. In 
this connection, the analysis of the efficiency of the proposed investment object is an integral part of the investment process. With an incompetent analysis and assessment of the effectiveness of investment projects, often during their implementation, unexpected negative results appear, which are characterized by uncertainties and risks.

\section{MATERIALS AND METHODS}

In this connection, the issue of studying the methods for assessing the effectiveness of an investment project, taking into account the factors of uncertainty and risk, is relevant. Uncertainty is the inadequacy of information about the conditions for the implementation of an investment project, including the costs and results associated with it. Accordingly, the uncertainty associated with the possibility of adverse situations and consequences arising during the implementation of the project are characterized by the concept of risk. Project risks are possible changes in key project parameters that lead to the transformation of an effective project into an ineffective one. If, under different possible conditions, the implementation costs and results of the project are different, then in calculating the effectiveness of an investment project, risk factors and uncertainties must be taken into account [8-11]. There are the following types of uncertainty and investment risks:

- The risk associated with the instability of economic legislation and the current economic situation, investment conditions and profit use;

- External economic risk (the possibility of imposing restrictions on trade and supplies, closing borders, etc.);

- Uncertainty of the political situation, the risk of unfavourable socio-political changes in the country and the region;

- Inferiority or inaccuracy of information on the dynamics of technical and economic indicators. parameters of new equipment and technology;
- Fluctuations in market rates, prices, market conditions;

- Uncertainty of natural and climatic conditions, the possibility of natural disasters;

- Production and technological risk (accidents and equipment failures, production defects;

- Uncertainty of goals, interests and behaviour of participants;

- Inadequacy or inaccuracy of information on the financial position and business reputation of participating enterprises (the possibility of non-payments, bankruptcy, failure of contractual obligations).

Depending on the level of risk, special areas of investment activity can be characterized. The directions of the company's investment activities have a different nature, degree of responsibility and, accordingly, the nature of the consequences and levels of risk. In conditions of uncertainty, the set of technical and economic parameters (for example, productivity, equipment service life, etc.) of the project, and therefore its cash flow, are not exactly known and may be different. Accordingly, there are many possible scenarios for project implementation. And all of them must be taken into account. In practice, two accounting methods are used:

1. The project is evaluated under one, specially selected baseline scenario. The possibility of realizing other scenarios is taken into account by careful selection of the parameters of the baseline scenario and the system of indicators by which this baseline scenario is assessed. This method is largely based on expert judgment and does not always provide sufficient accuracy. Therefore, it is permissible at the initial stages of project development.

2. When evaluating the project, all possible scenarios and "their degree of possibility" are taken into account. 
In the general case, the indicators that characterize the effectiveness of a project in general under all possible conditions of its implementation are called indicators of expected efficiency. The sustainability of a project is understood as its effectiveness under certain changes in the conditions of its implementation, that is when implementing alternative scenarios. Depending on how the project is being implemented under different scenarios, we can talk about its absolute stability, sufficient stability or its instability. The project is considered:

- Stable if it is effective in all scenarios;

- Sufficiently stable if it turns out to be ineffective only under those possible scenarios that have a sufficiently small "degree of possibility";

- Unstable if it turns out to be ineffective or leads to adverse consequences in scenarios with a sufficient degree of possibility.

The stability of the project is largely ensured by the organizational and economic mechanism of its implementation, which provides for the elements that carry out its "stabilization":

- Redundancy (for example, projects may provide for reserves of production capacities, stocks of raw materials and supplies, etc.);

- Insurance;

- Adaptation, which manifests itself in a change in the function of the project participants and the parameters of the actions they perform (adaptation can be ensured by changing the terms of mutual settlements between project participants, for example, by hedging transactions or indexing prices for goods and services supplied to each other, changing the volumes, structure and nomenclature manufactured products in the event of hazardous situations);

- Liquidation procedures, which should ensure the most effective liquidation of the enterprise, the most complete satisfaction of the requirements of other project participants and contractors;

- Taking into account the subsequent information (ie the organizational and economic mechanism of the project implementation should be formed so that the project "reacts" to the additional information coming in during its implementation).

\section{Uncertainties are taken into account by the following methods:}

1. Aggregated assessment of stability.

2. Calculation of boundaries and levels of break-even.

3. Method of variation of parameters.

4. Evaluation of the expected efficiency of the project, taking into account the uncertainties.

\section{The aggregate sustainability assessment} method is subdivided into:

- An integrated assessment of sustainability for the investment project as a whole;

- An integrated assessment of the sustainability of the project for its participants.

An enlarged assessment of sustainability for an investment project as a whole, or a criterion for the sustainability of an investment project as a whole. The stability of the enlarged project as a whole to possible deviations of cash receipts and costs from the planned ones can be assessed by comparing the internal discount rate (IRR) for the project as a whole (as part of the commercial efficiency indicators) with the discount rate adopted for this project, including the risk premium.

- The risk premium is an increase in the discount rate by including a risk adjustment (in percentage).

- The discount rate that takes into account the risk is the maximum of such discount rates when using which at least one alternative and accessible direction of investment, which has the same risk as this 
project, will provide him with a nonnegative integral discounted effect.

- The risk premium is determined by an expert method. The sum without the risk interest rate and risk premium is used to discount the project's cash flows, from which the net present value (NPV) of the projects is calculated. A project with a large NPV is considered preferable.

An enlarged assessment of the sustainability of the project for its participants. The stability of the investment project from the point of view of the enterprise participating in the project with possible changes in the conditions of its implementation can be checked based on the results of calculations of commercial efficiency for the baseline scenario of the project by analyzing the dynamics of real money flows.

The general criterion for the sustainability of the project as a whole and its participants. The project is recommended to be assessed as sustainable if its parameters are moderately pessimistic and include the necessary reserves of financial feasibility, the discount rate takes into account the risk at each step during the operation of the enterprise; the accumulated compounded (with no risk discount rate) cash flow balance is at least $5 \%$ of the amount of net operating costs and the investments made at this step.

Compounding is the opposite of discounting, it is the process of determining the future value of cash flows based on their present value. If the discounting of capital is carried out according to the formula $\mathrm{K}=\mathrm{K}_{\mathrm{t}}{ }^{*} \mathrm{dt}$, then compounding is carried out according to the formula $K_{t}=K / d t$, where: $K_{t}$ is the future value of funds; $K$ is the current value; $d_{t}$ - discount factor.

\section{Calculation of boundaries and break-even levels.}

The break-even boundary of the project parameter for a certain step of the calculation period is determined as such a coefficient to the value of this parameter at this step when applied, the participant's net profit at this step becomes zero. One of the important indicators of this type is the break-even level.

The break-even level (break-even point) is the sales volume (production volume), at which the proceeds from the sale of products coincide with the production costs. When determining this indicator, it is assumed that production costs can be divided into conditionally fixed and conditionally variable. The break-even point is determined by the formula:

$$
T_{61}=3_{c}:\left(\left\lfloor-3_{v}\right),\right.
$$

where: $3_{c}$ - conditionally fixed costs (not changing when the volume of production changes); $3 v-$ conditionally variable costs (changing in direct proportion to the volume of production); C - product price (c - product unit price).

To maintain the efficiency of the project, the break-even point must be less than the values of the nominal volumes of production and sales: the further from them the value of the break-even point (in percentage), the more stable the project. A project is considered sustainable if, in the calculations for the project as a whole, the break-even level does not exceed $0.7-0.8$ after the development of the design capacity. The project is considered sustainable, from the point of view of the participant, if the break-even level does not exceed 1.0 after the development of the design capacity and 0.6 after the completed calculations for the investment loan. It should be noted that such indicators correspond to scenarios of a possible change in project parameters and reflect the impact of these changes on profit and NPV, but they do not relate to indicators of the efficiency of an investment project, and their calculation does not replace the calculation of integral indicators. Accounting for uncertainties by the method of variation of parameters [12-15]. Adjustment of the project parameters and the economic standards used in the calculation, 
replacing their design values with the expected ones also takes into account the uncertainty of the project implementation conditions. For this purpose:

- The terms of construction and other works are increased by the average amount of possible costs;

- The average increase in the cost of construction is increasing due to mistakes of the design organization;

- Delay in payments, irregularity in the supply of raw materials and materials, unplanned equipment failures, technology violations committed by personnel, paid and received fines and other sanctions for violation of contractual obligations are taken into account;

- If insurance of participants against investment risks is not provided, then the costs include the expected losses from this risk;

- As part of indirect financial results, the influence of investment risks on third-party enterprises and the population is taken into account;

- The discount rate and the required IRR increase.

The criterion of project sustainability for this method is higher than in the first method of accounting for uncertainty and consists in the fact that the project is considered to be stable concerning possible changes in parameters if, for all considered scenarios, NPV is positive and the necessary reserve of the project's financial feasibility is provided. The 4th method is considered the most accurate - this is an assessment of the expected efficiency of the project, taking into account uncertainty factors. The method includes the following steps:

- A description of the entire set of possible conditions for the implementation of the project (either in the form of scenarios or in the form of a system of restrictions on the values of the main technical, economic and other parameters of the project) and the costs corresponding to these conditions (including sanctions and costs associated with insurance and reservations), results and performance indicators;

- Transformation of the initial information on uncertainty factors into information on the probabilities of individual conditions of implementation and the corresponding performance indicators or on the intervals of their change;

- Based on the indicators of individual scenarios, generalized indicators of the expected efficiency are determined.

The main indicators used to compare various investment projects or project options and choose the best one are the indicators of the expected integral effect of $\ni_{\text {ож (economic - at }}$ the level of the national economy, commercial - at the level of an individual participant). The same indicators are used to substantiate the rational size and forms of reservation and insurance. If the probabilities of various conditions for the implementation of the project are known exactly, then the expected integral effect is calculated using the mathematical expectation formula:

$$
\ni_{\text {ож }}=\sum \ni_{i} * P_{i}
$$

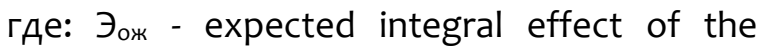
project;

$\ni_{i}$ - integral effect (NPV) in the i-th scenario;

$\mathrm{P}_{\mathrm{i}}$ - вероятность реализации і-того сценария.

In general, it is recommended to calculate the expected integral effect using the formula:

$$
Э_{\text {ож }}=d * \ni_{\max }+(1-d) * \ni_{\text {min }}
$$

Where: $\ni_{\max } и \ni_{\min }$ - the largest and the smallest of the mathematical expectations of the integral effect for admissible probability distributions, $\mathrm{d}$ is a special standard for taking 
into account the uncertainty of the effect, reflecting the system of preferences of the corresponding economic entity under conditions of uncertainty.

For example, there are two scenarios for project implementation - normal, in which the project effect $=100 \%$, and emergency, in which it turns out to be $20 \%$. If the probability of the normal scenario is 0.8 , and the emergency scenario, respectively, is $1-0.8=0.2$, then the expected effect of the project will be:

$$
\phi^{c}(t)=-K^{c}(t)+B^{c}(t)-3^{c}(t)-H^{c}(t)-\Delta O^{c}(t)+C^{c}(t)
$$

Where: $\mathrm{K}$ - drop volume Fixed asset investments;

$\mathrm{B}$ - revenue;

3 - operating costs excluding taxes and interest on loans;

$\mathrm{H}$ - taxes;

$\Delta \mathrm{O}$ - increase (increment) of working capital;

$\mathrm{C}$ - the balance of payments on the loan.

c - the superscript shows that the cash flow element is determined taking into account inflation (for forecast purposes).

To eliminate the distortion of the result caused by general inflation, we apply the procedure for defiling cash flows; for this, we divide the above expression (4) by the general inflation index - GJt at step $t$ (i.e., for the period from the initial point 0 to the end $t$ of the calculation step period). This procedure is called a defilement. Defiling the elements of cash flows is the purification of the elements of cash flows from inflation, including bringing the prices taken into account in the calculation step to the price level in the initial step.
$0,8 * 100-0,2 * 20=76 \%$

An important element in determining the effectiveness of investment projects is taking into account inflationary processes, and the comparison of indicators at different times is carried out by discounting. Discounting is the comparison of indicators of different times by bringing them to value in the initial period. In calculations, this is done by introducing defiling factors corresponding to the general inflation index. Initially, the undiscounted effect of the project at step $t$ is determined by the formula:
Provided that inflation is homogeneous and the increase in working capital can be neglected, and $c=0$, after defiling we get the effect:

$$
\phi^{\prime}(t)=\phi^{c}(t) / G J_{t}
$$

By discounting these effects $\phi^{c}(t)$ and $\phi^{\prime}(t)$, i.e. making a comparison of indicators of different times by bringing them to the value in the initial period, make sure that inflation does not affect the efficiency of the project. But in the case of heterogeneous inflation, a multi-currency project, the presence along with own borrowed funds and a noticeable effect of working capital, defiling does not completely eliminate the impact of inflation on the parameters of the project and indicators of its effectiveness. In this case, inflation should be taken into account by recalculating income and expenses in national currency into foreign currency and, accordingly, we introduce the following designations:

- The general inflation index GJt, expressed in national currency, is denoted by $J G\left(T_{t}\right.$, o); 
- Index of general inflation in foreign currency, we denote by $\mathrm{J}_{\mathrm{s}}\left(\mathrm{T}_{\mathrm{t}}, 0\right)$;

- $\phi_{{ }_{H}}^{\prime}(\mathrm{t}), \phi_{\mathrm{s}}^{\prime}(\mathrm{t})$ - respectively, damped national and foreign currency effects at the t-th step;

- $J_{x}\left(T_{t}, 0\right)$ - basic index of the rate of the national currency to foreign currency at the t-th step;

- $X^{c}(t)$ is the forecast rate of the national currency against a foreign currency at step $t$, which is determined by the formula:

$$
X^{c}(t)=X^{c}(0) * J_{x}\left(T_{t}, t_{0}\right)
$$

To transfer from the national currency effect to the foreign exchange effect, it is necessary to convert all prices in national currency into foreign currency, dividing them by $X^{c}(t)$, and $G J$ $t$ in the denominator of equation (5), to replace with $J_{s}\left(T_{t}, 0\right)$, then we get :

$$
\not b_{s}(t)=\not{ }^{\prime}{ }_{H}(t) * I\left(T_{t}, t_{0}\right) / X(0)
$$

Where:

$$
I\left(T_{t}, t_{0}\right)=J_{g}\left(T_{t}, t_{0}\right) / J_{s}\left(T_{t}, t_{0}\right) * J_{x}\left(T_{t}, t_{0}\right)
$$

The value I $\left(T_{t}, t_{0}\right)$ is called the index of internal inflation of the foreign currency, which shows how accurately the exchange rate index $I_{x}$ monitors the ratio of the indices of general inflation in the national currency $\left(\mathrm{J}_{\mathrm{g}}\right)$ and in foreign currency $\left(J_{s}\right)$. If I $\left(T_{t}, t_{0}\right)$ is the same at two adjacent steps of the billing period, then the currency price of the product within the country at the first step changes at the same rate as in the world market. If this index grows, the change in the foreign exchange price within the country at the first step lags behind its change in the external market. If the index decreases, then the currency price of the product changes faster in the domestic market than in the external one.

From formula (8) it follows that if the index I $\left(T_{t}, t_{0}\right)$ remains constant throughout the entire accounting period, then the IRR, ID should be the same for the total cash flows expressed in national and foreign currencies, and the "currency" NPV is different from national division by $\mathrm{X}(0)$.

It should be noted that if the index of domestic inflation of foreign currency changes in an arbitrary way, then there may not be simple dependencies between the performance indicators in national and foreign currency terms.

\section{CONCLUSION}

The long-term impact of inflation depends primarily on its heterogeneity and on the rate of domestic inflation of foreign exchange. General inflation indices affect only some taxes, and this usually has a minor effect on the efficiency of investment projects. With the short-term impact of inflation, an increase in the headline inflation index increases the impact of accounts receivable and payable. In the first case, the NPV of the project decreases, and in the second it increases. Therefore, even with uniform inflation, neglecting its influence can lead to a significant error, especially in projects with large payment delays.

\section{REFERENCES}

1. Decree of the President of the Republic of Uzbekistan of 07.04.2014, No.-UP4609, "On additional measures to further improve the investment climate and business environment in the Republic of Uzbekistan", Tashkent.

2. Decree of the President of the Republic of Uzbekistan dated March 31, 2017, No.-UP-4996, "On the formation of the State Committee of the Republic of 


Uzbekistan for Investments",
Tashkent.
Resolution of the President of the
Republic of Uzbekistan dated
03.15.2017, No.-PP-2836, "On improving
the quality of development of pre-
project documentation for investment
projects", Tashkent.

4. File archive for students. (n.d.). StudFiles. Retrieved December 23, 2020, from https://studfile.net

5. Nurmatov, A. G. (2019). Investment is the heart of the economy of Uzbekistan. Nurmatov, A.G. (2019). [Investment is the heart of uzbekistan economy. Problems of modern science and education, (12-1 (145)).] Problems of modern science and education, (12-1 (145)).

6. Atabaeva Zamira Abduzhalilovna (2019). Organization of investment accounting for capital investments. Problems of modern science and education, (12-1 (145)), 58-63. doi: 10.24411 / 2304-2338-2019-11205.

7. Khojayev AS (2016) The main directions of the development of farms specialized in fruits and vegetables in Uzbeksitan. ISJ Theoretical \& Applied Science, 12 (44): 24-28. Soi: http://s-oi.org/1.1/TAS-12-44-5 Doi: http://dx.doi.org/10.15863/TAS.2016.12.

44.5

8. Temirkulov Alisher Abduraimovich (2019). State management of investment activities. Problems of modern science and education, (12-2 (145)), 97-101.

9. Atabaeva, Z. A., \& Khojaev, A. S. (2020). Investment activity and analysis of investment projects. ISJ Theoretical \& Applied Science, 05 (85), 714-720. Soi. http://s-o-i.org/1.1/TAS-05-85-129, Doi: https://dx.doi.org/10.15863/TAS

10. Ismanov Ibrokhim Nabievich, Khozhaev Azizkhon Saidalokhonovich, \& Khabizhonov Salohiddin Kakhramonjon Ugli (2019). Improving the accounting of intangible assets. Problems of modern science and education, (6 (139)), 79-81.

11. Tashpulatov A. Modern forms of selfemployment under conditions of recession// ISJ Theoretical \& Applied Science, Volume 85, Issue 5, (May 2020) (2020) 05 (85), P.452-455. Soi: http://s-o-i.org/1.1/TAS-05-85-84 Doi: https://dx.doi.org/10.15863/TAS.2020.0 5.85.84.

12. Najmiddin, T., \& Saidalohonovich, K. A. (2020). About the origin and development of the universe, man, and accountability. Journal of Critical Reviews, 7(13), 1763-1769.

13. Azizkhon, K. (2017). The peculiarities of statistical analysis on fruit and vegetable farming (Fergana Region is as an example). Bulletin of Science and Practice, (8 (21)).

14. Hakimova, S., Habijonov, S., \& Hojaev, A. (2018). Statistical prognosis of the production of fruits and vegetables grown by farmers in the Fergana region. Bulletin of Science and Practice.

15. Khojaev, A. S., \& Akramova, N. M. (2017). The ways of development and statistic analysis of farmers'activities specialized in fruit-vegetables production in the ferghana region. In Economics, management and law: innovative problem solving (pp. 45-47). 